\title{
Avaliação da Capacidade de Autodepuração do Rio das Mortes no Município de Vassouras/RJ
}

\author{
Pedro Ricciardone \\ Universidade Severino Sombra, Centro de Ciências \\ Exatas, Tecnológicas e da Natureza, Curso de Engenharia \\ Ambiental, pedroricciardone@ig.com.br \\ Orlando dos Santos Pereira \\ Universidade Federal Rural do Rio de Janeiro, Departamento de \\ Matemática, orlandopereira@ufrrj.br \\ Cristiane de Souza Siqueira Pereira \\ Universidade Severino Sombra, Centro de Ciências \\ Exatas, Tecnológicas e da Natureza, Curso de Engenharia \\ Ambiental, crispereiraeq@ufrj.br
}

\begin{abstract}
Resumo: Este trabalho apresenta uma simulação matemática da capacidade de autodepuração do Rio das Mortes no Município de Vassouras/RJ utilizando o modelo de Streeter-Phelps. A simulação do modelo é comparada com os dados experimentais medidos em campo de oxigênio dissolvido (OD) e da demanda bioquímica de oxigênio (DBO). Os resultados obtidos apresentam o grau de poluição do corpo d'água e o comprimento necessário para que o mesmo recuperasse os níveis adequados de $O D$ e DBO, apenas por processos naturais, e retornasse a estabilidade.
\end{abstract}

Palavras-chave: Autodepuração. Qualidade da água. Streeter-phelps

\section{Evaluation of the Capacity Self-purification of Rio das Mortes in the City of Vassouras/RJ}

\begin{abstract}
This paper presents a mathematical simulation of self-purification capacity of Rio das Mortes in Vassouras, RJ, using the Streeter-Phelps model. The model simulation is compared with experimental data measured in dissolved oxygen field (DO) and biochemical oxygen demand (BOD). The results show the degree of pollution of the water body, as well as what would be the length required to recover appropriate levels of $D O$ and $B O D$, by natural processes only, and return to stability.
\end{abstract}

Keywords: Self-purification. Water quality. Streeter-phelps. 


\section{Introdução}

O crescimento populacional desacelerado, as atividades industriais e outras atividades humanas exigem, cada vez mais, o uso da água. De acordo com Teles e Silveira (2006), o aumento por essa demanda ocasiona a geração de resíduos líquidos que são muitas vezes lançados in natura nos corpos hídricos, alterando assim suas características naturais. O lançamento de um efluente líquido em um rio provoca um consumo de oxigênio dissolvido sendo necessários teores mínimos de oxigênio dissolvido nos rios para a existência da biodiversidade do corpo hídrico.

Leitão (2001) cita que, no Brasil, o problema não está na quantidade de água disponível, uma vez que é um país privilegiado nesse aspecto, mas sim na qualidade dessa água, reflexo de um passado de gestão inadequada. Desse modo, há necessidade de manejo adequado dos recursos hídricos, de forma a garantir água na quantidade e na qualidade desejáveis aos seus múltiplos usos.

A introdução de matéria orgânica em um curso de água resulta no consumo de oxigênio dissolvido. Isso se deve aos processos de estabilização da matéria orgânica realizados pelas bactérias decompositoras, as quais utilizam o oxigênio disponível no meio líquido para a sua respiração. O decréscimo da concentração de oxigênio dissolvido tem diversas implicações do ponto de vista ambiental, constituindo-se em um dos principais problemas de poluição das águas (Hespanhol, 2009).

Segundo Von Sperling (2005), o fenômeno da autodepuração está vinculado ao restabelecimento do equilíbrio no meio aquático, por mecanismos essencialmente naturais, após as alterações induzidas pelos despejos afluentes. O conceito de autodepuração apresenta a mesma relatividade que o conceito de poluição. A água pode ser considerada depurada mesmo que não esteja totalmente purificada em termos higiênicos, apresentando, por exemplo, organismos patogênicos.

De acordo com Dezotti (2008) a degradação e metabolização por microorganismos da matéria orgânica presente em um despejo ocorre quando esse é lançado naturalmente

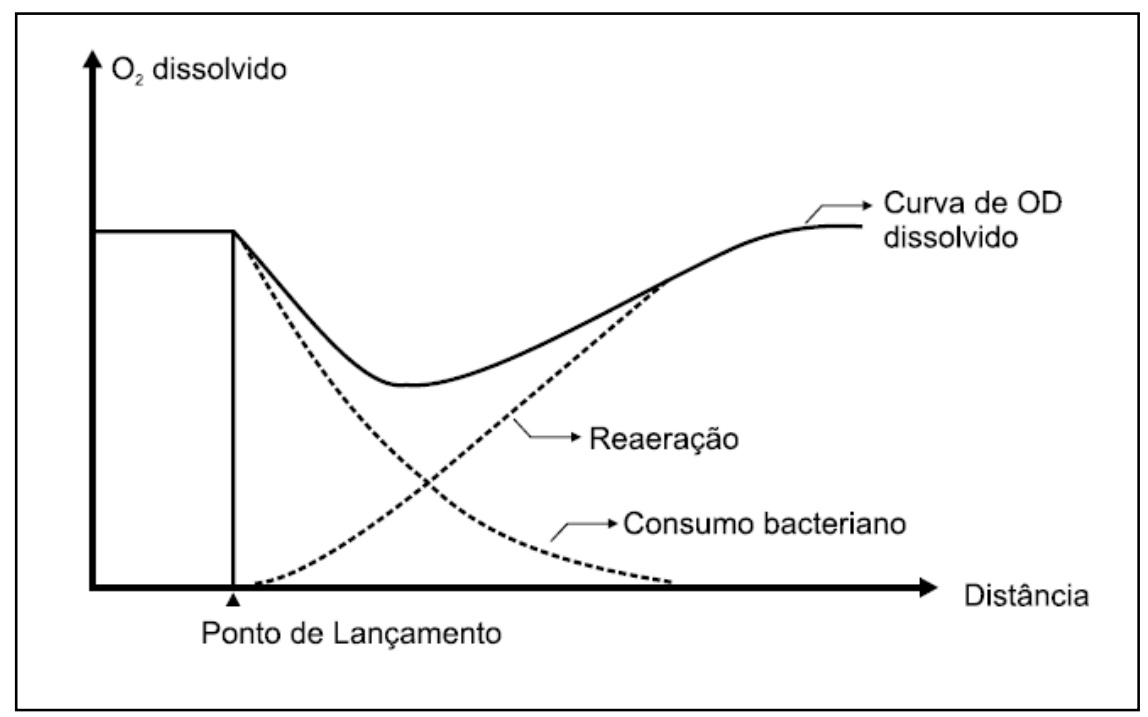

Figura 1. Efeito do lançamento de um efluente sobre o oxigênio dissolvido de um curso de água Fonte (Dezotti, 2008) 
em um curso de água. A Figura 1 abaixo ilustra o efeito do lançamento de um efluente biodegradável sobre o nível de oxigênio dissolvido de um corpo receptor, onde é possível observar que, próximo ao lançamento do efluente, se concentra uma população microbiana que consome as substâncias orgânicas consumindo o oxigênio dissolvido da água.

De acordo com essa mesma autora, a curva de concentração de OD é resultante de dois mecanismos principais, sendo o primeiro mecanismo o consumo de oxigênio pelas bactérias para degradação das substâncias poluentes e o segundo, que é o da reaeração natural do curso de água, consiste na transferência do oxigênio do ar para o líquido.

O modelo de Streeter-Phelps (1925) é precursor entre os modelos numéricos de qualidade de água. Foi primeiramente aplicado em 1925, em um estudo sobre o Rio Ohio, com o objetivo de aumentar a eficiência das ações a serem tomadas no controle da poluição. Esse modelo contribuiu para o surgimento de outros modelos numéricos como QUAL I e II QUAL-2E (Fischer, 1995) e QUAL-2K (Chapra, 2006).

Tal modelo é constituído por duas equações diferenciais ordinárias: uma modela a oxidação da parte biodegradável da matéria orgânica e a outra o fluxo de oxigênio proveniente da dinâmica da reaeração atmosférica. Essas equações são nomeadas equações de demanda bioquímica de oxigênio e equação de reaeração, respectivamente. $\mathrm{O}$ oxigênio dissolvido tem sido utilizado tradicionalmente para a determinação do grau de poluição e de autodepuração em cursos d'água, sendo seu teor expresso em concentrações quantificáveis e passíveis de modelagem matemática (Von Sperling, 2005).

Vários autores citam o modelo de Streeter-Phelps como um modelo simples, uma vez que para sua determinação, são considerados apenas, como valores de entrada, os parâmetros de OD e de DBO, além do fato de considerar o sistema como mistura completa. Além de Teles e Silveira (2006) outros autores utilizaram o modelo de Streeter Phelps em estudos de modelagem de autodepuração, tais como Nunes (2008) e Hespanhol (2009) entre outros.

O interesse em estudar a autodepuração do Rio das Mortes é a contrapartida da Universidade Severino Sombra (USS) para com a cidade de Vassouras/RJ e com a comunidade em geral, devido ao fato da mesma estar situada no centro da cidade e em local que abrange o rio estudado. Dessa forma, o presente trabalho teve o objetivo de avaliar, em termos da depleção de oxigênio dissolvido, a capacidade de autodepuração do Rio das Mortes, utilizando o modelo matemático de Streeter-Phelps (1925).

\section{Metodologia}

\section{Descrições dos Pontos de Amostragem}

O município de Vassouras/RJ se desenvolve entre vales drenados por cursos d'agua de pequeno porte, todos afluentes do Rio das Mortes. Este rio é a principal drenagem da sede do município.

Para atingir a região central, percorre em galeria, a Rua Osvaldo de Almeida Ramos, umas das mais movimentadas da cidade, onde se localizam diversos bares e restaurantes e a Universidade Severino Sombra. Em seguida, atravessa o centro da cidade, conflui com a drenagem da Rua Nilo Peçanha e segue, ainda em galeria, até poucos metros à jusante 
da Praça Martinho Nóbrega, quando volta a se escoar a céu aberto, desaguando no Rio Paraíba do Sul.

O Rio das Mortes recebe esgoto doméstico bruto, sem tratamento, de diversas casas ao longo de sua extensão, até seu encontro com o Rio Paraíba do Sul. Foram escolhidas três áreas, através das análises de imagens de satélite de acordo com a Figura 2 abaixo.

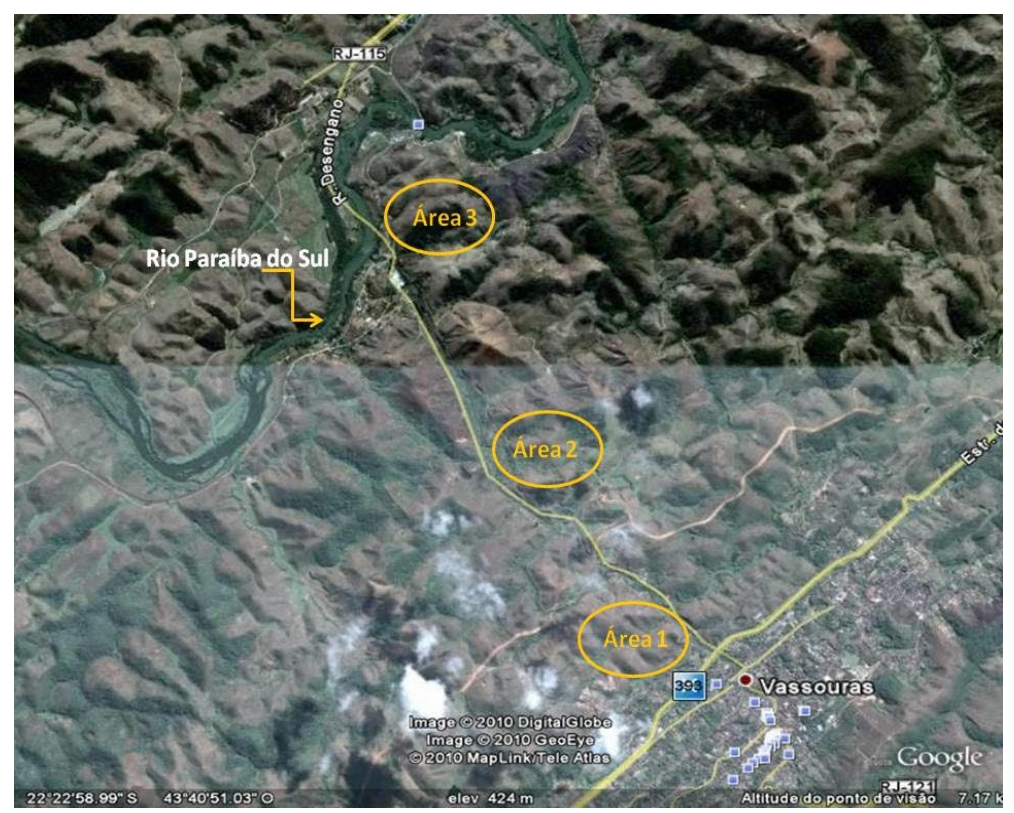

Figura 2. Locais de Amostragem (Google Earth, 2010)

De acordo com a Figura acima, a área 1 corresponde à área de maior recebimento de despejos escoando-se a céu aberto. A área 2 está localizada no meio do percurso e é caracterizada por fazendas ao seu redor. A área 3 é onde o Rio das Mortes deságua no Rio Paraíba do Sul, principal rio da região. Do ponto 1 ao encontro com o Rio Paraíba do Sul, a extensão do Rio das Mortes é de aproximadamente $7 \mathrm{Km}$. O objetivo do trabalho foi verificar se após o maior despejo de esgoto, o Rio das Mortes se depurava antes de desaguar no Rio Paraíba do Sul. Não foram visualmente encontrados pontos de lançamento de esgoto no rio após o ponto 1, mas é provável que esses lançamentos existam, devido a fazendas e casas nas margens do rio.

As amostragens ocorreram nos períodos de chuva (Março/2011) e seca (Agosto/2011) com o objetivo de avaliar o comportamento do processo de autodepuração nessas duas épocas do ano.

As amostras foram coletadas em recipientes plásticos, com volume de 2 litros. Foi utilizada caixa de isopor com gelo para acondicionamento das amostras até que fossem conduzidas ao laboratório, no prazo não superior a 24 horas. A coleta foi feita mergulhando o frasco e rinçado duas a três vezes nas águas onde foram realizadas as coletas. As medições de temperatura e oxigênio dissolvido foram realizadas no local com auxílio de um oxímetro digital.

As análises foram feitas gentilmente por um laboratório de análises de água de uma Indústria Siderúrgica. Os pontos de coleta de amostras de água para análises de vazão, DBO, OD e temperatura do rio estão demonstrados abaixo. 


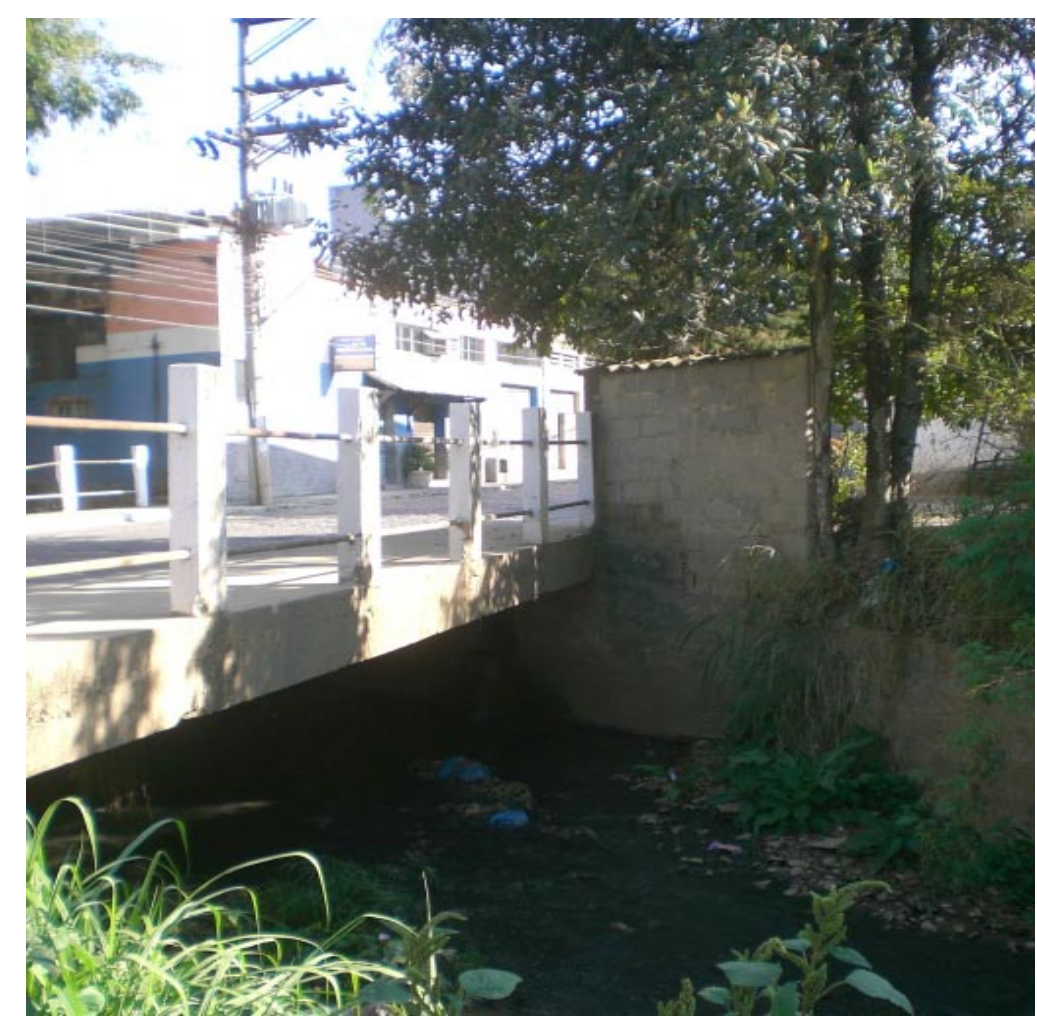

Figura 3. Ponto 1

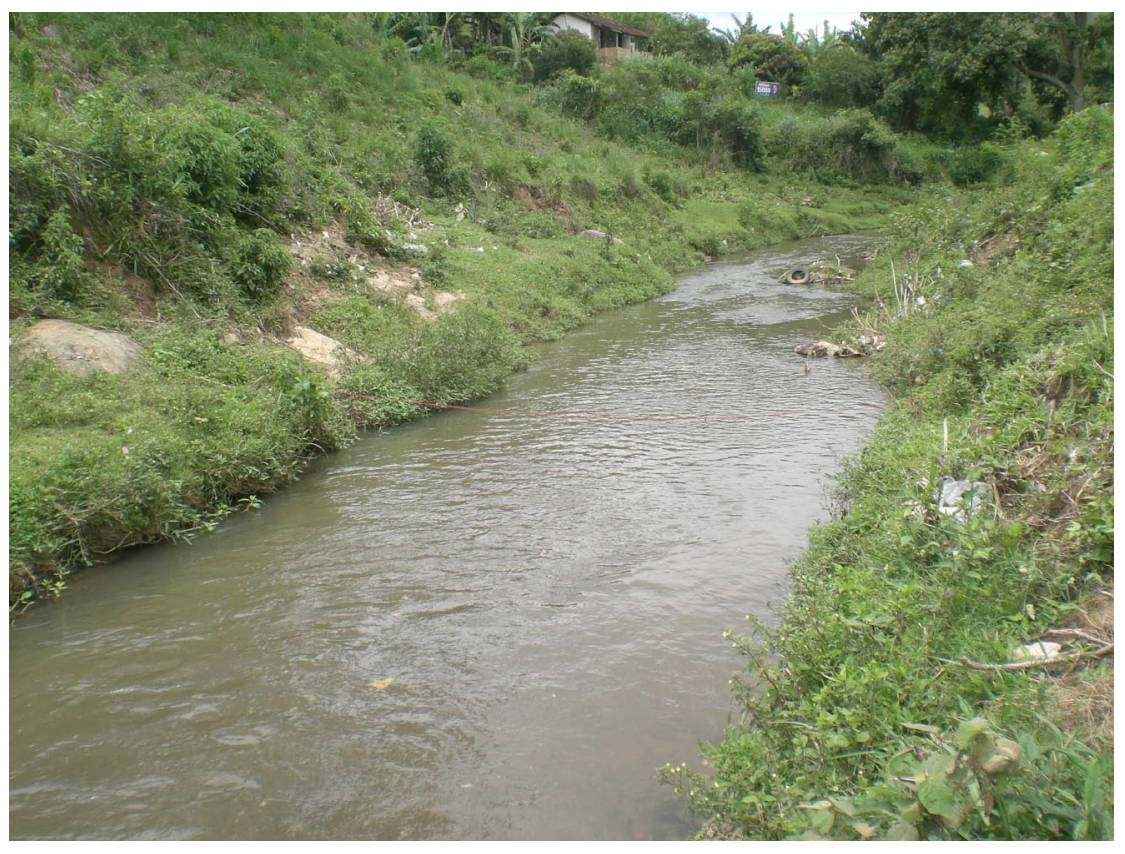

Figura 4. Ponto 2 


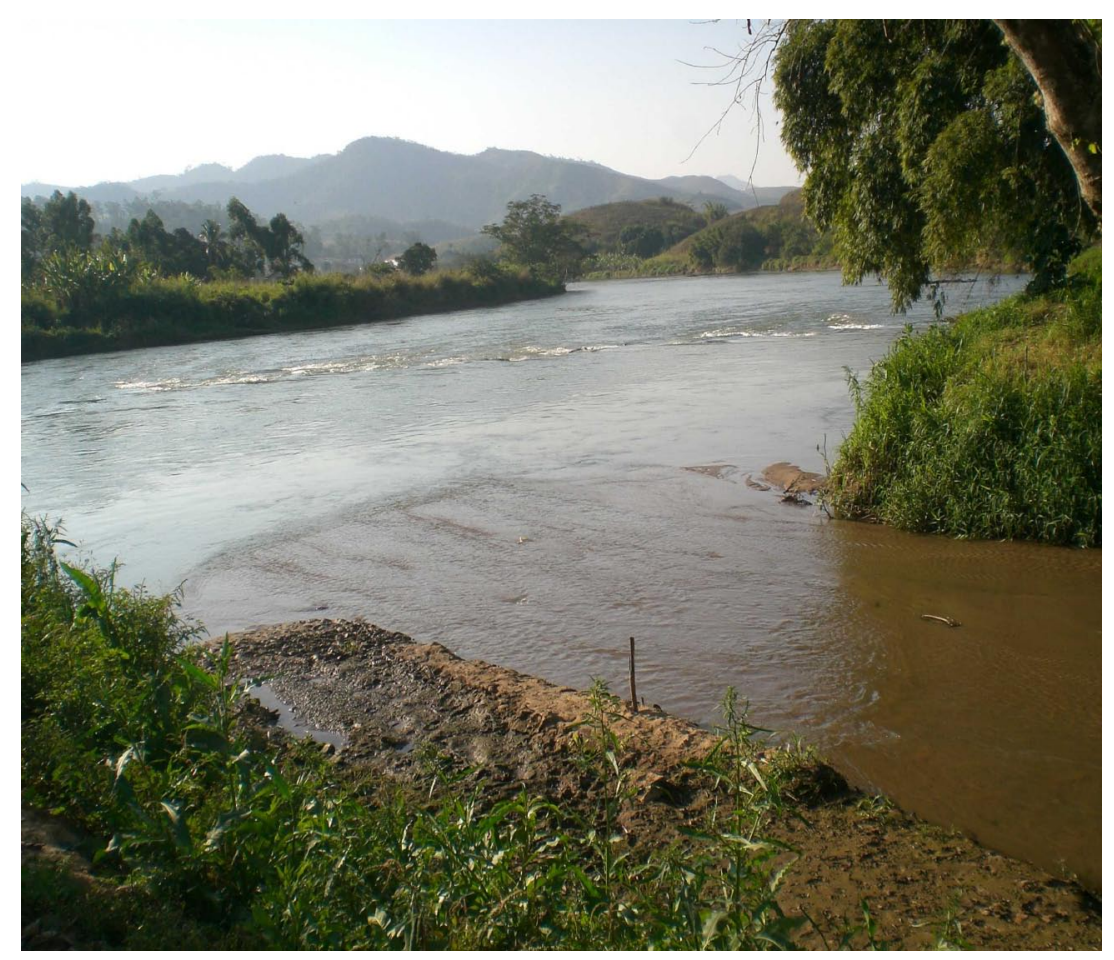

Figura 5. Ponto 3

O método utilizado para determinação da vazão durante a realização deste trabalho foi o método da medição com flutuadores e seguiu metodologia experimental de acordo com o Comunicado Técnico da Embrapa (2007). O método consiste em determinar a velocidade de deslocamento de um objeto flutuante, medindo-se o tempo necessário para que o mesmo se desloque num trecho do rio de comprimento conhecido. É um método muito utilizado pela sua simplicidade, sobretudo, na ausência de equipamentos sofisticados que apresentam custos elevados.

\section{Modelagem Matemática - Modelo de Streeter-Phelps}

A estrutura desenvolvida por esses autores (conhecida como o modelo de Streeter-Phelps) é clássica dentro da Engenharia Ambiental, servindo de suporte para todos os outros modelos mais sofisticados que o sucederam. Os dados de entrada e de saída utilizados no modelo de Streeter-Phelps para o cálculo da autodepuração, segundo Von Sperling (2005) e utilizados para o presente trabalho estão apresentados a seguir.

a) Vazão do curso d'água (Qr);

b) Vazão de esgotos (Qe);

c) Oxigênio dissolvido no rio, à montante do lançamento (ODr);

d) Oxigênio dissolvido no esgoto (ODe);

e) $\mathrm{DBO}_{5}$ no rio, à montante do lançamento (DBOr);

f) $\mathrm{DBO}_{5}$ do esgoto (DBOe);

g) Coeficiente de desoxigenação $\left(\mathrm{K}_{1}\right)$; 
h) Coeficiente de reaeração $\left(\mathrm{K}_{2}\right)$;

i) Tempo de percurso (t);

j) Concentração de saturação de $\mathrm{OD}(\mathrm{Cs})$;

k) Oxigênio dissolvido mínimo permissível (ODmin).

É necessário conhecer as características da bacia hidrográfica de estudo e temperatura (água). Com posse dessas informações, o processo de cálculo do modelo se dá através da seguinte equação, em função do tempo:

$$
C_{t}=C_{S}-\left[\frac{K_{1} L_{0}}{K_{2}-K_{1}} \cdot\left(e^{-K_{1} \cdot t}-e^{-K_{2} \cdot t}\right)+D_{0} \cdot e^{-K_{2} \cdot t}\right]
$$

em que:

$\mathrm{C}_{\mathrm{t}}=$ Concentração de oxigênio ao longo do tempo (mg/L);

$\mathrm{C}_{\mathrm{s}}=$ Concentração de saturação de oxigênio $(\mathrm{mg} / \mathrm{L})$;

$\mathrm{D}_{0}$ - déficit inicial de oxigênio dissolvido, no ponto de mistura $(\mathrm{mg} / \mathrm{L})$;

$\mathrm{t}$ - tempo (dia);

$\mathrm{K}_{1}$ - coeficiente de desoxigenação $\left(\mathrm{d}^{-1}\right)$;

$\mathrm{K}_{2}$ - coeficiente de reaeração $\left(\mathrm{d}^{-1}\right)$;

$\mathrm{L}_{\mathrm{o}}$ - demanda última de oxigênio, logo após a mistura $(\mathrm{mg} / \mathrm{L})$.

\section{Resultados e Discussões}

\section{Determinação da Vazão}

A medição da vazão do Rio das Mortes foi realizada nas faixas que compreendem os pontos de estudo do presente trabalho nos períodos de chuva e seca.

Por se tratar de um rio com fundo pedregoso foi utilizado o coeficiente de 0,8 para corrigir os cálculos, de acordo com o Comunicado Técnico da Embrapa (2007).

$\mathrm{Na}$ época de chuva não foi possível realizar a medição na região do ponto três devido às cheias do Rio Paraíba do Sul. Por esse motivo foram simulados apenas o ponto 1 e 2 nessa época. A Tabela 1 abaixo apresenta os resultados do cálculo da medição da vazão do Rio das Mortes nos períodos estudados. 
Tabela 1. Medição da Vazão $\left(\mathrm{m}^{3} / \mathrm{s}\right)$ do Rio das Mortes pelo método flutuador

\begin{tabular}{ccc}
\hline Pontos de Coleta & Período Chuva (Março/2011) & $\begin{array}{c}\text { Período Seca } \\
\text { (Agosto/2011) }\end{array}$ \\
\hline Ponto 1 & 0,11 & 0,08 \\
Ponto 2 & 0,47 & 0,13 \\
Ponto 3 & $*$ & 0,10 \\
\hline
\end{tabular}

*Valor não medido

De acordo com a tabela é possível constatar a diminuição da vazão na época de seca.

\section{Determinação da Concentração de Oxigênio Dissolvido e Demanda Bioquímica de Oxigênio}

Os resultados de OD e DBO do Rio das Mortes nos pontos de coleta estão apresentados nas Tabelas 2 e 3, respectivamente. Estes resultados são utilizados como dados de entrada no modelo.

Tabela 2. Concentração do Oxigênio Dissolvido (mg/L)

\begin{tabular}{ccc}
\hline Pontos de Coleta & $\begin{array}{c}\text { Período Chuva } \\
\text { (Março/2011) }\end{array}$ & $\begin{array}{c}\text { Período Seca } \\
\text { (Agosto/2011) }\end{array}$ \\
\hline Ponto 1 & 6,2 & 2,0 \\
\hline Ponto 2 & 9,2 & 8,0 \\
\hline Ponto 3 & 7,6 & 6,4 \\
\hline
\end{tabular}

*Valor não medido

Tabela 3. Concentração da Demanda Bioquímica de Oxigênio (mg/L)

\begin{tabular}{lcc}
\hline Pontos de Coleta & $\begin{array}{c}\text { Período Chuva } \\
\text { (Março/2011) }\end{array}$ & $\begin{array}{c}\text { Período Seca } \\
\text { (Agosto/2011) }\end{array}$ \\
\hline Ponto 1 & 31 & 176 \\
\hline Ponto 2 & 14 & 17 \\
\hline Ponto 3 & 18 & 31 \\
\hline
\end{tabular}

*Valor não medido

A menor concentração de OD e a maior concentração de DBO foram encontradas no ponto de coleta mais crítico, sendo esse o ponto 1, local de maior lançamento de esgotos, sem nenhum tipo de tratamento. Os outros pontos não apresentaram diferenças significativas.

A vazão dos esgotos domésticos foi obtida através de procedimentos convencionais, utilizando-se os dados de população da cidade, obtendo como resultado a vazão média 
de $0,04 \mathrm{~m}^{3} / \mathrm{s}$. De acordo com Von Sperling (1995), a concentração da $\mathrm{DBO}_{5}$ dos esgotos domésticos brutos tem um valor médio de $300 \mathrm{mg} / \mathrm{L}$ e esse foi o valor adotado para a simulação do modelo no presente trabalho.

\section{Coeficientes de Autodepuração}

Como não foi possível obter um valor experimental para os coeficientes $\mathrm{K}_{1}$ e $\mathrm{K}_{2}$, foram adotados valores presentes na literatura (Von Sperling, 1996). Foi adotado o valor de $0,30 \mathrm{~d}^{-1}$ para o coeficiente de desoxigenação $\left(\mathrm{K}_{1}\right)$. Para o coeficiente de reareação $\left(\mathrm{K}_{2}\right)$ foi adotado o valor de $1,61 \mathrm{~d}^{-1}$ Os coeficientes foram ajustados em função da temperatura do Rio $\left(23^{\circ} \mathrm{C}\right.$ época de chuva $)$ e $\left(24^{\circ} \mathrm{C}\right.$ época de seca $)$.

\section{Simulação da Modelagem de Streeter-Phelps}

Com o conhecimento dos dados de entrada necessários para aplicação do modelo, através da equação 1, obtiveram-se os seguintes resultados simulados para o período de chuva (Março/2011), expressos no gráfico abaixo.

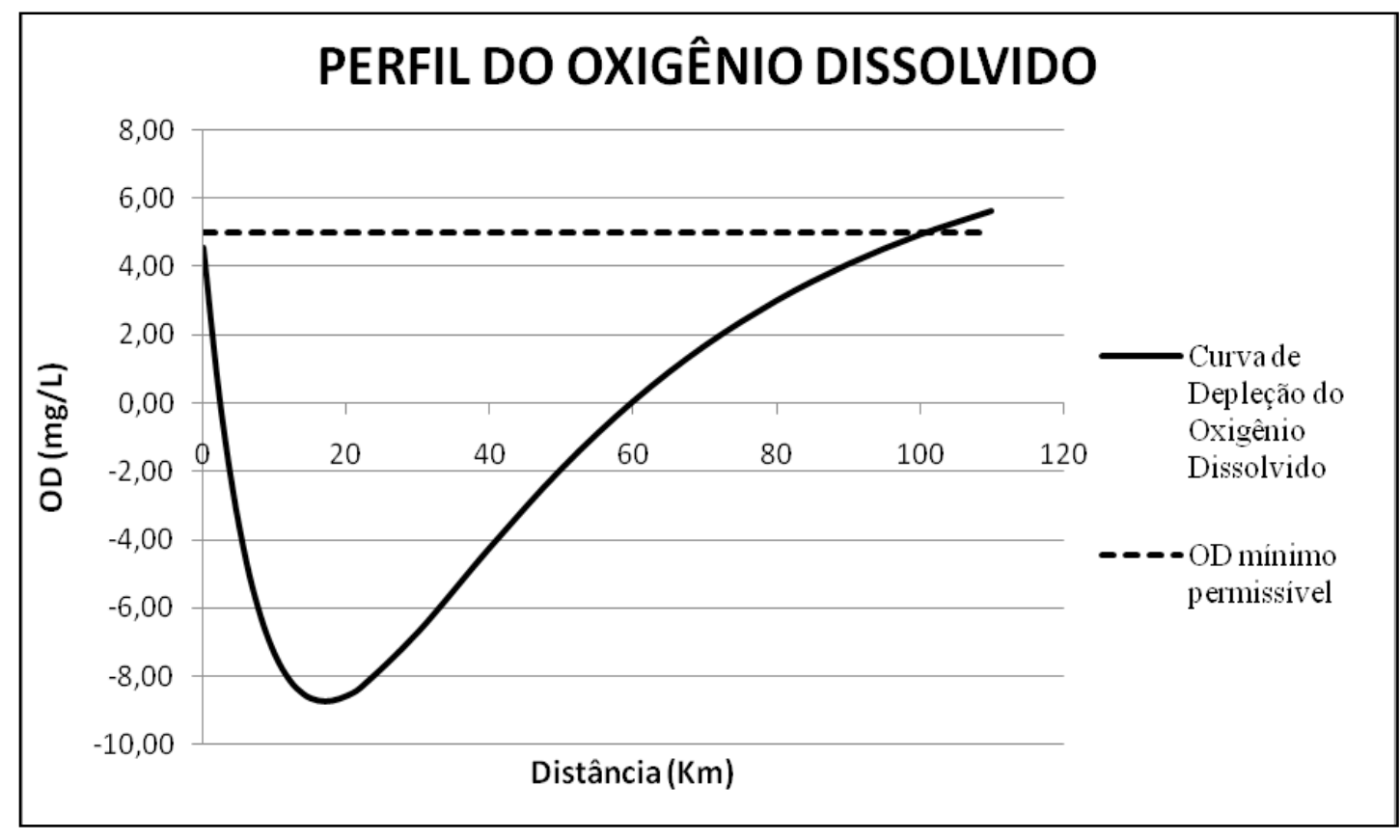

Figura 6. Curva de depleção de oxigênio obtida para a simulação do Ponto 1 no período de chuva (Março/2011)

De acordo com o gráfico na Figura 6 acima, a concentração crítica de oxigênio é menor que a mínima permitida, estabelecida pela Resolução 357/2005 da CONAMA. Esses valores variam em função da classe em que o corpo d' água está classificado. O teor mínimo permissível de Oxigênio Dissolvido nos corpos de água doce, classificados como de classe 2, assim como o Rio das Mortes se inclui, é de $5 \mathrm{mg} / \mathrm{L}$.

As concentrações negativas não têm significado físico. De acordo com Von Sperling (1996) o modelo de Streeter-Phelps não é válido a partir do momento em que o $\mathrm{OD}=$ 0mg/L O cálculo e o gráfico devem ser interrompidos nesse ponto, pois se considera que 
o modelo atingiu condições de anaerobiose em que o modelo não é mais válido. Porém os resultados são importantes devido à necessidade de medidas de controle ambiental. Segundo Nunes (2008) o lançamento de esgoto não é permitido neste local.

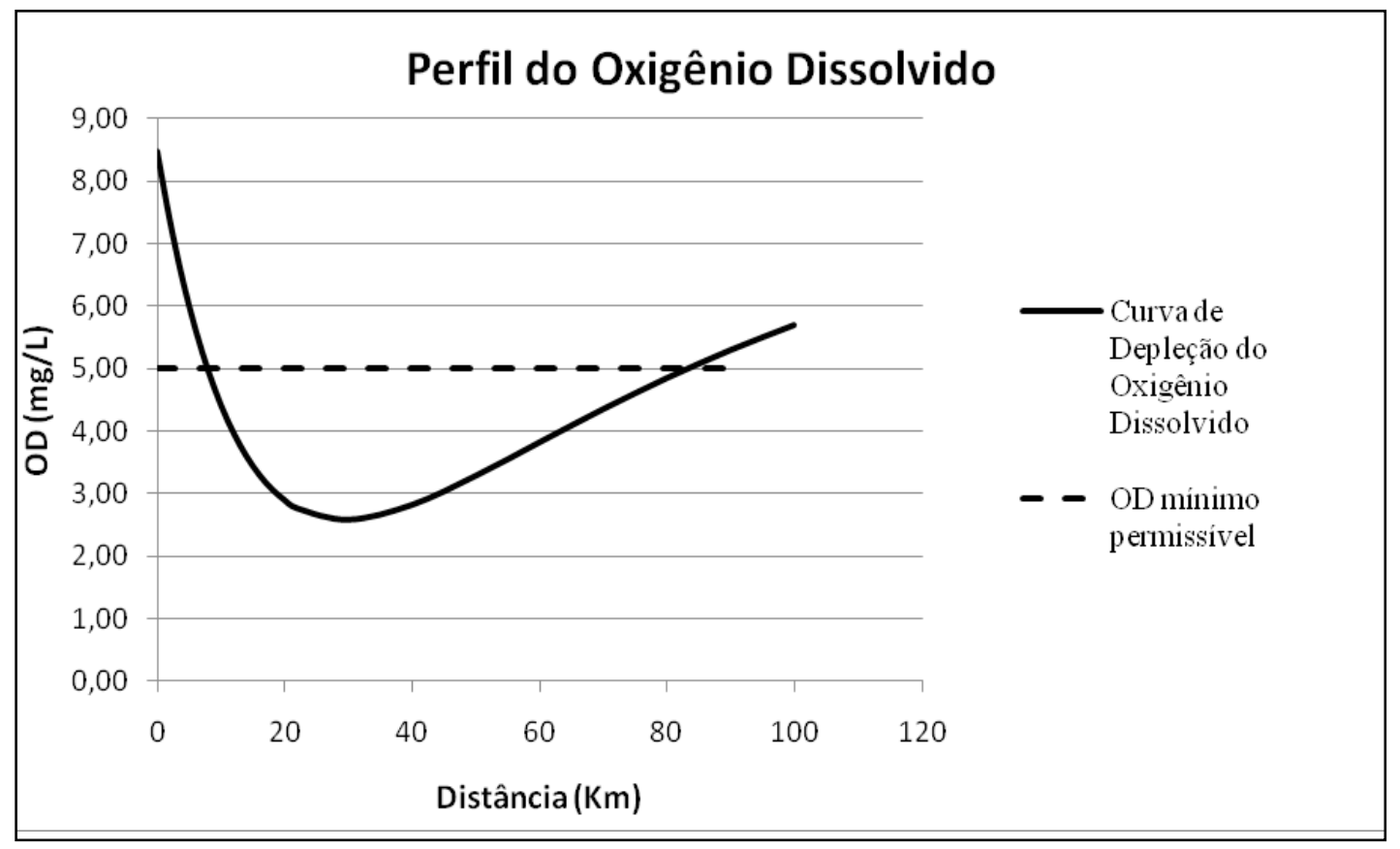

Figura 7. Curva de depleção de oxigênio obtida para a simulação do Ponto 2 no período de chuva (Março/2011)

No gráfico da Figura 7, que simula o ponto 2, a concentração crítica de OD também está abaixo do permissível e o Rio das Mortes necessitaria de cerca de $80 \mathrm{Km}$ para alcançar novamente o mínimo de estabilidade, ou seja, OD de $5 \mathrm{mg} / \mathrm{L}$, porém o mesmo possui uma extensão aproximada de 7,0 km até o Rio Paraíba do Sul. Sendo assim, não consegue depurar toda a carga de poluentes que recebe, afetando também as condições de estabilidade desse ambiente.

Com o conhecimento dos dados de entrada necessários para aplicação do modelo, através da equação 1, obtiveram-se os resultados simulados, para o período de seca (Agosto/2011), expressos a seguir, nos pontos de coleta 1,2 e 3 . É possível observar o mesmo perfil de OD nas três simulações. 


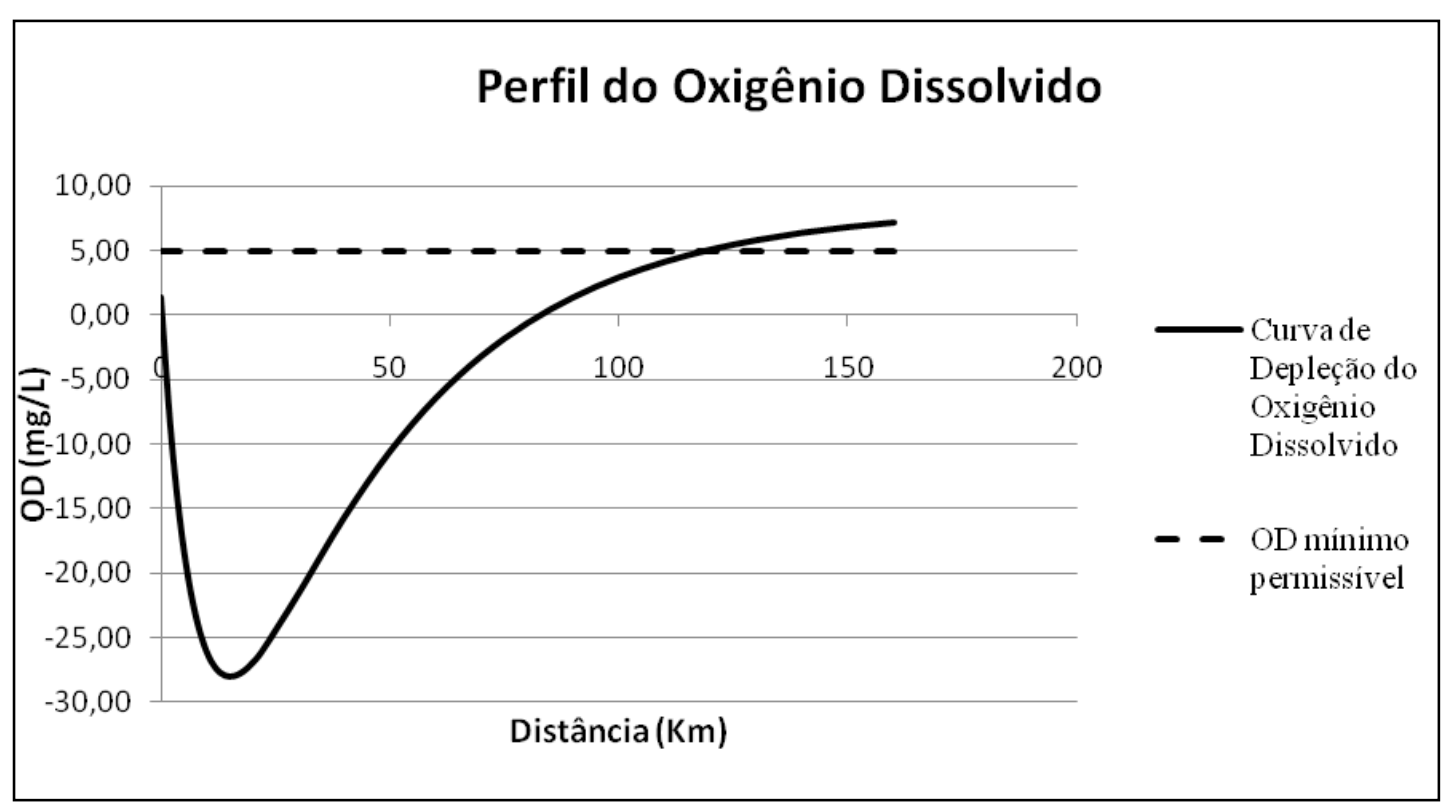

Figura 8. Curva de depleção de oxigênio obtida para a simulação do Ponto 1 no período de seca (Agosto/2011)

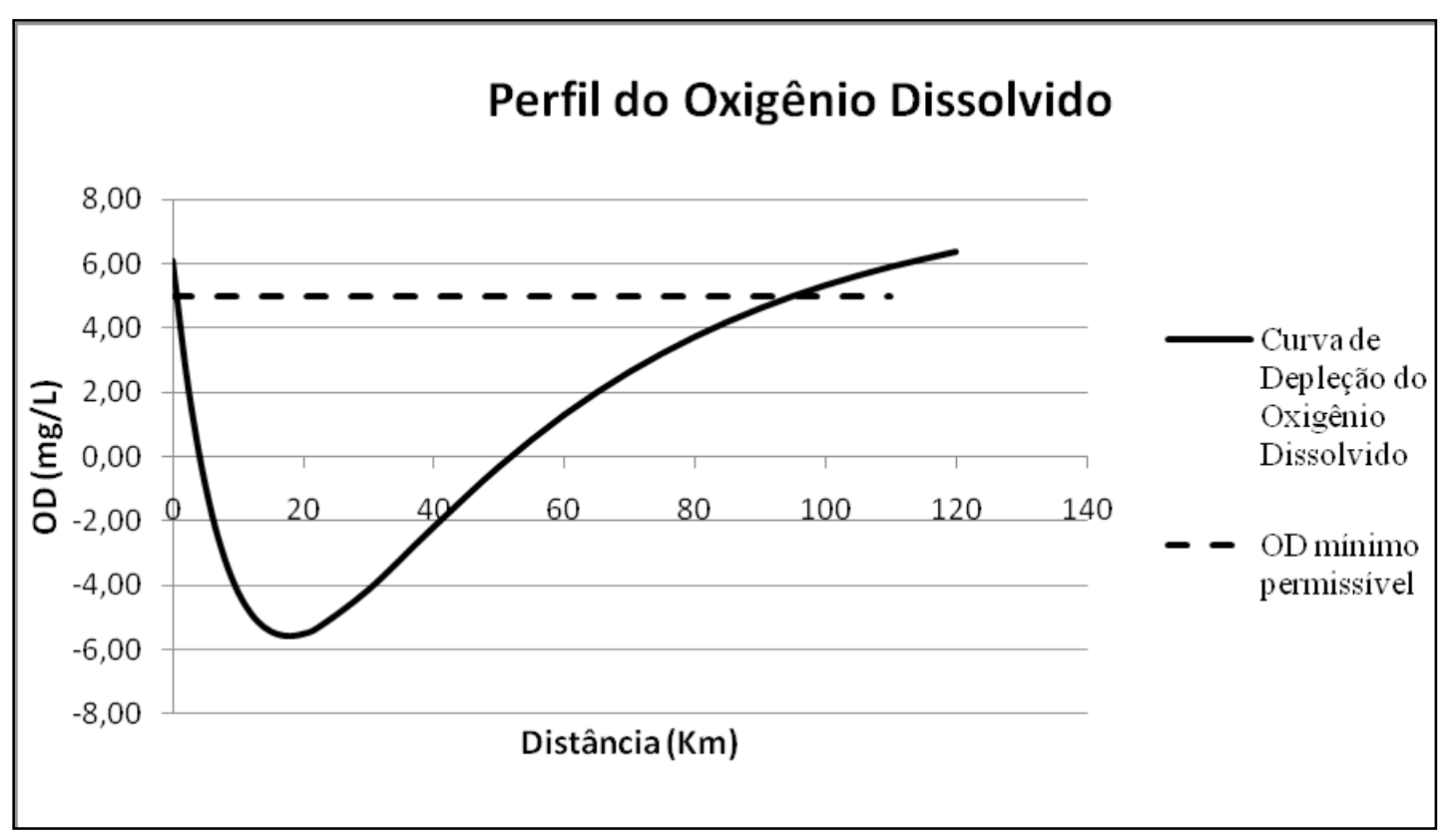

Figura 9. Curva de depleção de oxigênio obtida para a simulação do Ponto 2 no período de seca (Agosto/2011) 


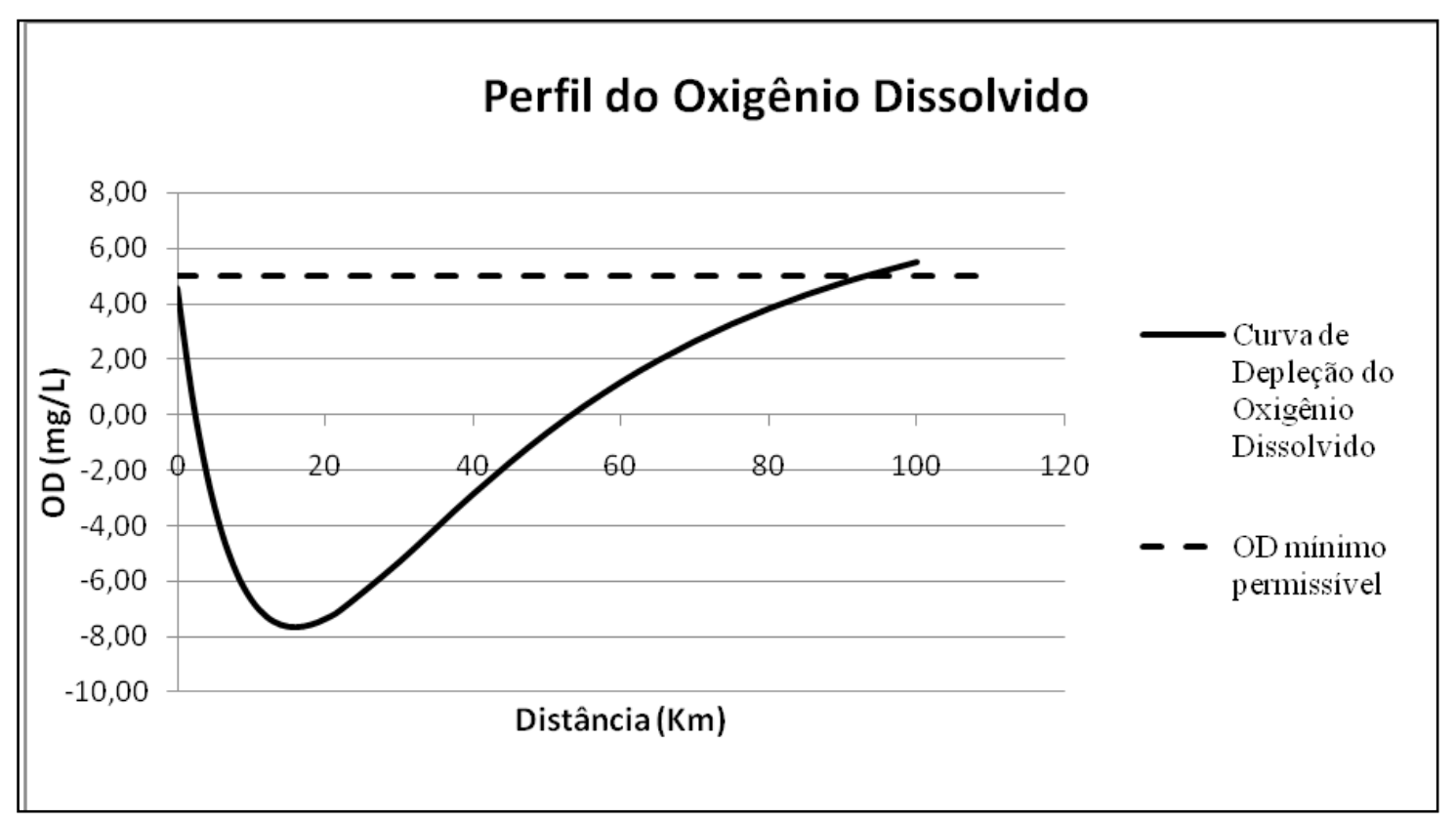

Figura 10. Curva de depleção de oxigênio obtida para a simulação do Ponto 3 no período de seca (Agosto/2011)

Portanto, como reportado na Figura 6 do ponto 1, no período chuvoso, as concentrações negativas não têm significado físico e considera-se que o modelo atingiu condições de anaerobiose em que o mesmo não é mais válido.

Verifica-se que, mesmo a uma distância de aproximadamente $50 \mathrm{Km}$, em todas as simulações, a concentração de oxigênio dissolvido ainda está abaixo do valor mínimo permitido para os rios de classe 2, ou no limite estabelecido e, portanto, o Rio das Mortes não está conseguindo depurar a carga de esgoto que é lançada em suas águas pela população, podendo comprometer a qualidade da água do Rio Paraíba do Sul. Com relação à distância, seria necessário uma extensão média acima de $60 \mathrm{Km}$ para que o Rio das Mortes atinja a estabilidade.

\section{Conclusão}

O modelo de Streeter-Phelps é um modelo simples, sendo necessário para sua determinação apenas valores de entrada como concentração de OD e de DBO. No caso do trecho analisado, o Rio das Mortes apesar de apresentar uma concentração normal de OD, o mesmo não atinge a estabilidade, necessitando de uma maior área para que ocorra sua autodepuração. As entradas pontuais de esgotos oriundos de casas e fazendas ao longo do trecho do rio retardam a recuperação desse perfil de OD. O ideal seria localizar todas as fontes poluidoras existentes à montante do trecho de estudo e apresentarem-se propostas alternativas de tratamento de todos os efluentes lançados junto ao Rio das Mortes. Outro ponto importante para que o modelo simule de forma satisfatória as condições reais do ponto de estudo, é em relação aos coeficientes de desoxigenação e o de reaeração. A determinação experimental de ambos e principalmente de $\mathrm{K}_{2}$ é de extrema importância para que o modelo seja utilizado com êxito. Quanto aos enquadramentos dos corpos 
d'água, através dos resultados da Demanda Bioquímica de Oxigênio, pode-se notar que sendo o Rio das Mortes enquadrado como um rio de Classe 2, o mesmo não atende os limites mínimos necessários exigidos por lei, segundo Resolução CONAMA 357/05, que limita o valor de $\mathrm{DBO}<5,0 \mathrm{mg} / 1$. 


\section{Referências}

Chapra, S. C. (1997) Surface water quality modeling. McGraw-Hill,.

Conselho Nacional de Meio Ambiente (2005) - Resolução 357/05, disponível em www. mma.gov.br, Brasília-DF.

Dezotti, M. (2008) Processo e Técnicas para o Controle Ambiental de Efluentes Líquidos. Série Escola Piloto em Engenharia Química COPPE/UFRJ, v.5, editora e-papers. ISBN 978-85-7650-173-2.

Embrapa Comunicado Técnico, 455. Julho 2007. "Medição da vazão em rios pelo método do flutuador". Versão eletrônica.

Fischer, E. G. "Determinação de contaminação do ribeirão do Feijó através de levantamento de dados e modelo matemático de qualidade da água". São Carlos: Escola de Engenharia de São Carlos - Universidade de São Paulo, 1995. (Dissertação de Mestrado).

Hespanhol, K. M. H. (2008). "Monitoramento e diagnóstico da qualidade da água do Ribeirão Morangueiro". Universidade Estadual de Maringá. Dissertação de Mestrado.

Leitão, S. M.(2001). A Visão da água: o desafio do milênio. Belo Horizonte: Ecolatina.

Nunes, Daniele Gonçalves. (2008). "Modelagem da Autodepuração e qualidade da agua do rio Turvo Sujo". Universidade Federal de Viçosa. Dissertação de Mestrado.

Streeter, H. W., Phelps, E. B. (2005). "A study of the natural purification of the Ohio River.Public Health Bulletin 146, 1925”. Washington: Public Health Service..

Teles, Rafael Baldini e SILVEIRA, A. (2006). “Autodepuração de escoamentos naturais de água Estudo de caso: aplicação de modelagem matemática em um trecho do Ribeirão Preto." Ribeirão Preto-SP. In: XXX - Congreso da Associación Interamericana de Ingeniería Sanitaria y Ambiental - AIDIS 2006, 2006, Punta del Este. XXX - Congreso da Associación Interamericana de Ingeniería Sanitaria y Ambiental - AIDIS.

Von Sperling, M. (1996). Princípio do tratamento biológico de águas residuárias: introdução à qualidade das águas e ao tratamento de esgotos - Volume 1, 3a Edição revisada, DESA-UFMG, Belo Horizonte, MG.

Von Sperling, M. (2005). Princípios do tratamento biológico de águas residuárias. $3^{\mathrm{a}}$. ed. Belo Horizonte: Departamento de Engenharia Sanitária e Ambiental/UFMG. 